\title{
精梁機棫を支えるエンコーダ技術の進展
}

\section{電磁誘導式および光電式アブソリュート リニアエンコーダの最新技術* \\ New Technology of Electromagnetic and Optical Absolute Linear Encoder}

\section{森 洋篤柕林季*** 夜久 亭*** \\ Hiroatsu MORI, Kimitoshi ONO and Toru YAKU}

Key words

linear encoder, absolute linear encoder, electromagnetic linear encoder, optical linear encoder, computer numerical control, linear motor, full closed feedback

\section{1.は じめに}

リニアエンコーダは, 一定ピッチの目盛りをもつ直線状 の「スケール」に対して, 相対移動した「センサ」の変位 量をデジタル量として検出するシステムである。例えば磁 気式のリニアエンコーダでは，金属のスケール基材上に磁 石あるいは磁極が所定のピッチで配置されており，センサ が磁束という物理量の変動を検出することで移動量を検出 できる。 センサが検出しようとする物理量によってスケー ル基材上に配置される「目盛り」が異なり, 静電容量式で は平面電極が, 電磁誘導式では平面コイルが, また, 光電 式では光学格子がそれぞれ配置されている。 これら検出方 式には各々特徵があるが, 一般的には磁気式や電磁誘導式 など磁界を用いるものは污れに強く, 電極やコイルなど平 面的な構造の組み合わせでは安価に, また, 光学格子を用 いることで高精度・高分解能な特性が得られる ${ }^{1) 2}$.

これらのリニアエンコーダは, 精密工作機械, 半導体や 液晶分野などの各種製造装置, 三次元/画像測定機といっ た計測装置などにおいて，ステージなど可動部の位置検出 に広く利用されている。近年では, 装置の高速化や高剛性 化を狙って，回転モータとボールねじの組み合わせに代え てリニアモータを採用する事例が増加しており，フルクロ ーズドループ制御系における位置/速度の検出要素として リニアエンコーダが久かせないものになっている゙๋.

また、リニアエンコーダにはインクリメンタル (INC) リニアエンコーダとアブソリュート (ABS) リニアエン コーダの 2 種類がある. INCリニアエンコーダは, 単位 時間当たりの変位量をカウンタで積算して位置を求めてい る (相対位置計測).このため, ある位置で電源を切断し た後に電源を再投入すると, カウンタはゼロから計数を再 開するために電源切断時の相対位置を見失ってしまう。こ れに対しては，電源投入時に装置の原点復帰を行う（例え

*原稿受付 平成 28 年 7 月 4 日

**(株) ミットヨ研究開発本部商品開発部（川崎市高津区坂戸 1-20-1）

**** (株) ミツトヨ研究開発本部デイバイス技術開発部（川崎市高津区坂戸 1-201)
ば装置の移動リミットセンサまでセンサを移動させ，この 位置を基準としてカウンタにプリセットする）などして装 置の位置を確定する必要がある。このことから, スケール 上の絶対位置を常時検出することが可能な ABSリニアエ ンコーダが必要とされている.

ABS リニアエンコーダは, 1993 年に光電式と静電容量 式を複合させたタイプが世界で初めて市場に投入され4), 2004 年には電磁誘導式の ABS リニアエンコーダ5) が発売 されている。近年では各社からさまざまなタイプの ABS リニアエンコーダが販売されてきており活況を呈してい る $^{6)-11)}$.

本稿では, ABSリニアエンコーダのうち, 筆者らの開 発した電磁誘導式および光電式の 2 タイプについて検出原 理とその性能について述べる。

\section{2. 電磁誘導式 ABS リニアエンコーダの原理}

リニアエンコーダが使用されている工作機械や製造装置 では, 切削油や潤滑油，または結露による水滴がスケール やセンサに污れとして付着してしまうことがある. 静電容 量式や光電式のリニアエンコーダでは, その検出すべき物 理量の性質から污れに対して原理的に強いとはいえないた め, 污れの侵入を防ぐ構造的な対策や, 後述の撮像光学系 による光電式リニアエンコーダの開発を進めてきた。

一方で, 原理的に污れに強い検出方式であれば, 污れに 対する特別な配慮が不要となり, 使用者の安心感も大きく なる。そこで筆者らは，電磁誘導の原理を用いた ABSリ ニアエンコーダを開発した。図 1 は, 開発した電磁誘導 式 $\mathrm{ABS}$ リニアンコーダであり, ABS 検出長は最大 $6 \mathrm{~m}$

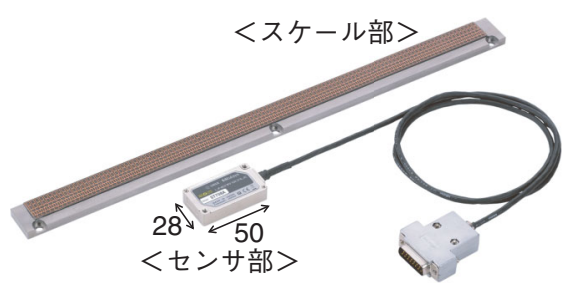

図 1 電磁誘導式 ABS リニアエンコーダ 
（a）コイル配置模式図

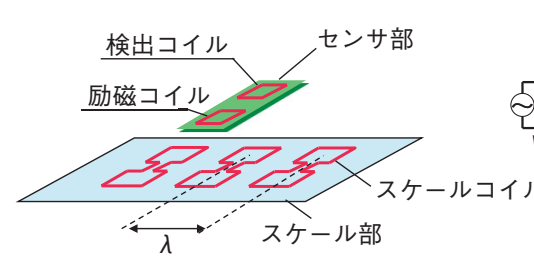

(c) 変位検出の原理 （b）電磁誘導の原理

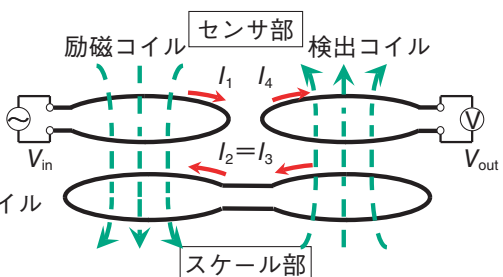

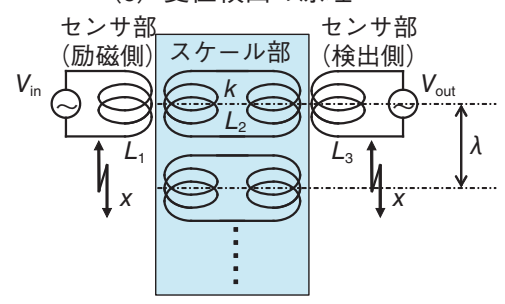

図 2 電磁誘導式リニアエンコーダの原理

表 1 電磁誘導式 ABS リニアエンコーダの主な仕様

\begin{tabular}{c|c}
\hline 有効測定長 & $100 \sim 6000(\mathrm{~mm})$ \\
\hline 分解能 & $0.1(\mu \mathrm{m})$ \\
\hline 指示精度 $\left(20^{\circ} \mathrm{C}\right)$ & $(5+5 \mathrm{~L} / 1000)(\mu \mathrm{m}) \quad \mathrm{L}$ : 有効測定長 $(\mathrm{mm})$ \\
\hline 最大応答速度 & $5(\mathrm{~m} / \mathrm{s})$ \\
\hline
\end{tabular}

である．表 1 に主な仕様を示す.

図 2 に電磁誘導式の原理図を示す。図 2 (a) に示す例 では，スケール部の二つのコイルは閉回路として結合し， センサ部の励磁/検出コイルと相互誘導で結合するような 位置で対向させている。ここで図 2 (b) に示すように, 励磁コイルに時間的に変化する電流 $I_{1}$ を流すと, 対向す るスケールコイルには発生した磁束を打ち消すように起電 流 $I_{2}=I_{3}$ が流れる. この電流 $I_{3}$ によって生じた磁束 $\Phi$ は, 対向する検出コイルに式（1）で表されるような誘導起電 力 $V_{\text {out }}$ を発生させる.

$$
V_{\text {out }}=-N \frac{d \Phi}{d t} \quad\left(\Phi \propto \mu \cdot I_{2} \quad N=1\right)
$$

$(\mu$ : センサとスケールに挟まれた空間の透磁率， $N$ ：コイ ルの巻数)

ここで, 図 2 (c) のようにスケールの長手方向に等間 隔入でスケールコイルが形成されていて，スケールとセ ンサのコイルが結合係数 $k$ で誘導結合されている場合，セ ンサ部がスケール長手方向に変位すると，式（2）で表さ れるような変位量 $x$ で変化する誘導起電力 $V_{\text {out }}$ が生じる.

$$
V_{\text {out }}(x)=k \cdot V_{\text {in }} \cdot \sqrt{\frac{L_{3}}{L_{1}}} \cdot \sin \frac{2 \pi}{\lambda} x
$$

( $V_{\text {in }}$ : 励磁電圧, $L_{1}, L_{3}$ : 自己インダクタンス)

このように，スケールとセンサの相対的な変位に応じて 電磁結合が変わり，得られる電圧が正弦波状に変化するこ とを利用して変位量を検出している。 また, 式（1）の透 磁率 $\mu$ は空気と水，油などでは大きな差異がないことか ら, 電磁誘導式は, 原理的に水や油, 磁性粉等の付着に対

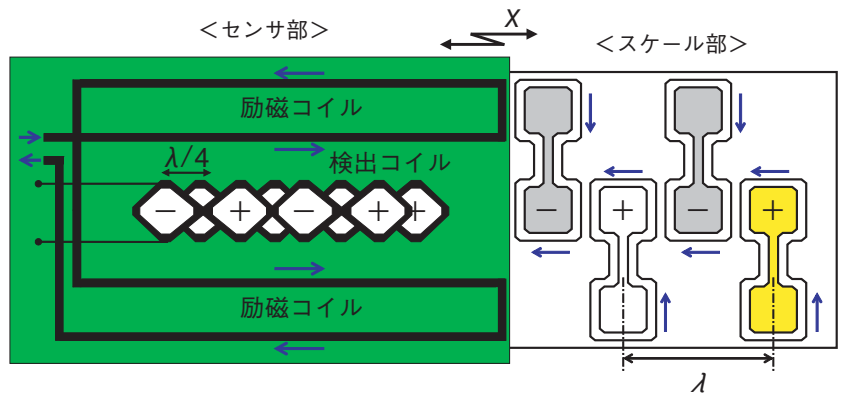

図 3 電磁誘導式検出部構成例

してロバストな変位検出方式となっている.

\section{3. 電磁誘導式 ABS リニアエンコーダの変位検出}

\section{1 変位検出の高精度化}

変位検出を高精度に行うためには，外部磁界の変動の影 響を受けにくく，ひずみの小さい正弦波信号を得ることが 重要である。図 3 は検出部のコイル構成例であるが，コ イル構成の主なポイントは以下の 3 点である。

(1) センサ部の検出コイルを挟んだ両側に 2 本の励磁コ イルと，それに対向する位置にスケールコイルを配置 する。それぞれの励磁コイルに流す電流の向きを反転 させることで, +側/一側に対称で, より正弦波に近 い交番磁界がスケールコイルで生成される。

(2) 検出コイルを+/ーのツイストペア化することで検 出信号を差動化する。これにより, 外部磁界の変化や ギャップ変動などの外乱要因にロバストになる。

(3) ツイストペアの検出コイルを複数並べてアレイ化す ることで平均化効果が得られ，パターンの部分的な欠 陥や寸法変動に対する影響を低減する。

以上の検出コイルを， $\lambda / 4$ ずらした位置にもう 1 組形成 すると, $X$ 方向の変位に伴い $90^{\circ}$ 度位相の異なる二相正弦 波信号 $V_{\mathrm{A}}, V_{\mathrm{B}}$ が得られ, 変位量 $x$ は式 (4) によって求め られる。 


$$
\begin{aligned}
& V_{\mathrm{A}}=A \cdot \cos \frac{2 \pi}{\lambda} x, \quad V_{\mathrm{B}}=A \cdot \sin \frac{2 \pi}{\lambda} x \quad(A: \text { 振幅 }) \\
& x=\frac{\lambda}{2 \pi} \tan ^{-1} \frac{V_{\mathrm{B}}}{V_{\mathrm{A}}}
\end{aligned}
$$

得られた信号 $V_{\mathrm{A}}, V_{\mathrm{B}}$ は, 一般的に $\mathrm{A} / \mathrm{D}$ コンバータで内 挿することで変位検出の高分解能化が図られているが, 分 解能を向上させるためには，それに見合った内挿誤差に抑 える必要がある.内挿回路では, 理想的な二相正弦波が得 られるとして処理を行っているが，実際の信号には振幅／ 中心電圧 /位相誤差や 3 次以降の高調波ひずみ誤差が含ま れ，内挿数が増えるにしたがってこの誤差は無視できなく なる ${ }^{12)}$ 。ここで，信号の補正を行うことが困難な 3 次の高 調波成分をキャンセルするために，筆者らは検出コイルを $\lambda / 3$ ずつシフトした 3 セット構成とし， $120^{\circ}$ 度位相がずれ た三相信号 $S_{\mathrm{a}}, S_{\mathrm{b}}, S_{\mathrm{c}}$ を得ている。 この信号に振幅 $B$ の 3 次高調波成分が含まれていたとすると， $S_{\mathrm{a}}, S_{\mathrm{b}}, S_{\mathrm{c}}$ は式（5） のように表される。

$$
\begin{aligned}
& S_{\mathrm{A}}=A \sin \frac{2 \pi}{\lambda}\left(x+\frac{\lambda}{3}\right)+B \sin \frac{2 \pi \cdot 3}{\lambda}\left(x+\frac{\lambda}{3}\right) \\
& S_{\mathrm{B}}=A \sin \frac{2 \pi}{\lambda} x+B \sin \frac{2 \pi \cdot 3}{\lambda} x \\
& S_{\mathrm{C}}=A \sin \frac{2 \pi}{\lambda}\left(x-\frac{\lambda}{3}\right)+B \sin \frac{2 \pi \cdot 3}{\lambda}\left(x-\frac{\lambda}{3}\right)
\end{aligned}
$$

この三相信号を使って式（6）のように変換すると 3 次 高調波の影響をキャンセルでき, 式 (3), 式 (4) と同様 に $90^{\circ}$ 二相正弦波信号から変位量が求められる.

$$
\begin{aligned}
& \frac{S_{\mathrm{A}}-S_{\mathrm{C}}}{\sqrt{3}}=A \cdot \cos \frac{2 \pi}{\lambda} x=V_{\mathrm{A}} \\
& \frac{2 S_{\mathrm{B}}-S_{\mathrm{A}}-S_{\mathrm{C}}}{3}=A \cdot \sin \frac{2 \pi}{\lambda} x=V_{\mathrm{B}}
\end{aligned}
$$

\section{2 絶対位置の検出}

実際のコイルの構成は, 絶対位置の検出を行うために, 信号周期 (波長) の異なる複数のコイルを備えている. 図 1 で示したエンコーダでは， $\lambda_{1}$ から $\lambda_{3}$ までわずかに波長 が異なる FINE, MEDIUM, COARSEの 3 トラックのコ イルで構成されている。この 3 トラックの周期信号から, さらに式（7）で示す 3 種類の波長 $\lambda_{\mathrm{FIN}}, \lambda_{\mathrm{MED}}, \lambda_{\mathrm{COA}}$ をもつ 信号を生成する。ここで, 各波長の波長比 $\lambda_{\mathrm{FIN}}: \lambda_{\mathrm{MED}}: \lambda_{\mathrm{COA}}$ は $1: K_{\mathrm{M}}: K_{\mathrm{M}} \times K_{\mathrm{C}}$ である

$$
\begin{aligned}
& \lambda_{\mathrm{FIN}}=\lambda_{1}, \lambda_{\mathrm{MED}}=\frac{\lambda_{2} \lambda_{1}}{\lambda_{2}-\lambda_{1}}=K_{\mathrm{M}} \cdot \lambda_{\mathrm{FIN}} \\
& \lambda_{\mathrm{COA}}=\frac{\lambda_{3} \lambda_{2}}{\lambda_{3}-\lambda_{2}}=K_{\mathrm{C}} \cdot K_{\mathrm{M}} \cdot \lambda_{\mathrm{FIN}}
\end{aligned}
$$

図 4 に絶対位置検出時の各トラックの位相関係を示す. 図中の〈検出位置〉での各トラックの位相を $\phi_{\mathrm{FIN}}, \phi_{\mathrm{MED}}$, $\phi_{\mathrm{COA}}$ とし, FINE, MEDIUM トラックでの波数を $n F, n M$ とすると，各々の波数は式（8）で表される.

$$
\begin{aligned}
& n F=\operatorname{Round}\left(K_{\mathrm{M}} \cdot \phi_{\mathrm{MED}}-\phi_{\mathrm{FIN}}\right) \\
& n M=\operatorname{Round}\left(K_{C} \cdot \phi_{\mathrm{COA}}-\phi_{\mathrm{MED}}\right)
\end{aligned}
$$

(Round は小数点以下を四捨五入した整数の意)

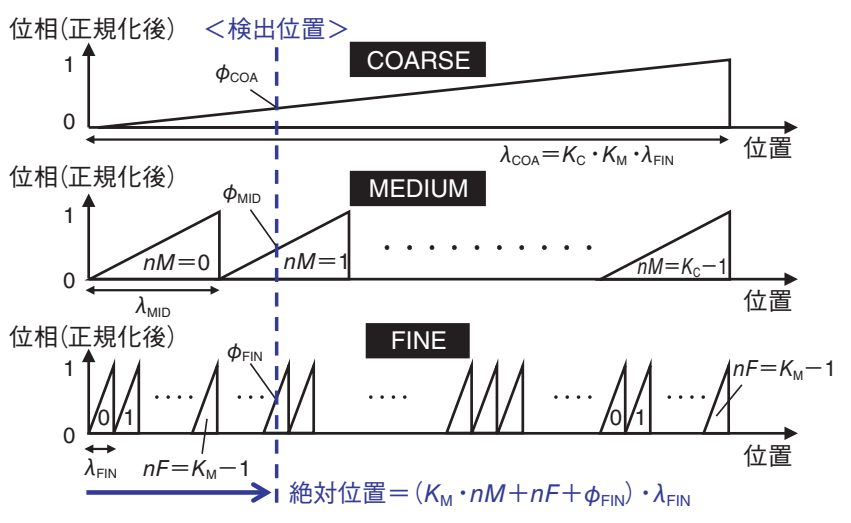

図 4 各トラックの位相関係

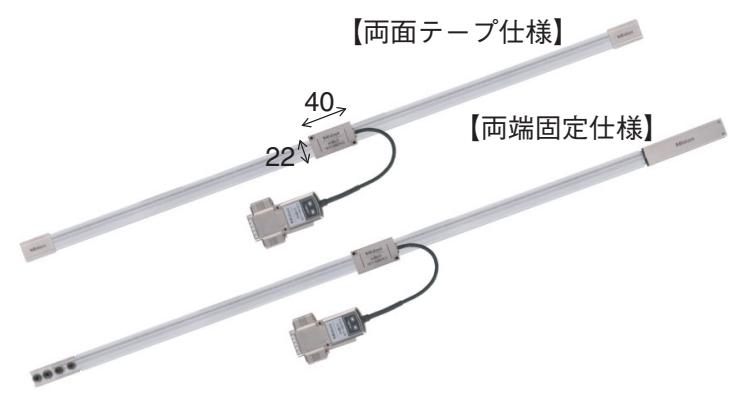

図 5 光電式 $A B S$ リンエンコーダ

表 2 光電式 ABS リニアエンコーダの主な仕様

\begin{tabular}{c|c}
\hline 有効測定長 & $100 \sim 12000(\mathrm{~mm})$ \\
\hline 分解能 & $1(\mathrm{~nm})$ \\
\hline 指示精度 $\left(20^{\circ} \mathrm{C}\right)$ & $8(\mathrm{~m} / \mathrm{m})$ \\
\hline 最大応答速度 & $\begin{array}{c}\text { メタルテープ }(\text { 厚さ }: 0.3(\mathrm{~mm})) \\
\text { (両面テープ仕様/両端固定仕様 })\end{array}$ \\
\hline スケールタイプ
\end{tabular}

最終的に，この〈検出位置〉での絶対位置は式（9）に て求められる。

絶対位置 $=\left(K_{\mathrm{M}} \cdot n M+n F+\phi_{\mathrm{FIN}}\right) \cdot \lambda_{\mathrm{FIN}}$

図 1 のエンコーダでは, $\lambda_{\mathrm{FIN}}=\lambda_{1}=3 \mathrm{~mm}, K_{\mathrm{M}}=32, K_{\mathrm{C}}$ $=64$ として最長で $6 \mathrm{~m}$ を超える範囲の $\mathrm{ABS}$ 検出を可能と している.

近年では, 電磁誘導式においても分解能や内挿精度の向 上が求められている。これに対しては，スケール素材のガ ラス化や信号補正方法の改良などで光電式に近いレベルに まで向上しており，今後の発展が期待できる。

\section{4. 光電式 $A B S$ リニアエンコーダの原理}

前述の電磁誘導式 ABS リニアエンコーダは, 本質的に 污れに強いエンコーダであるが，精密工作機械などから求 められている分解能 $1 \mathrm{~nm}$ には現時点では届いていない.

そこで筆者らは, 撮像光学系を用いることで光電式とし ては高い污れ耐性をもたせた ABSリニアエンコーダを開 発した。図 5 は, 開発した光電式 ABSリニアエンコーダ 


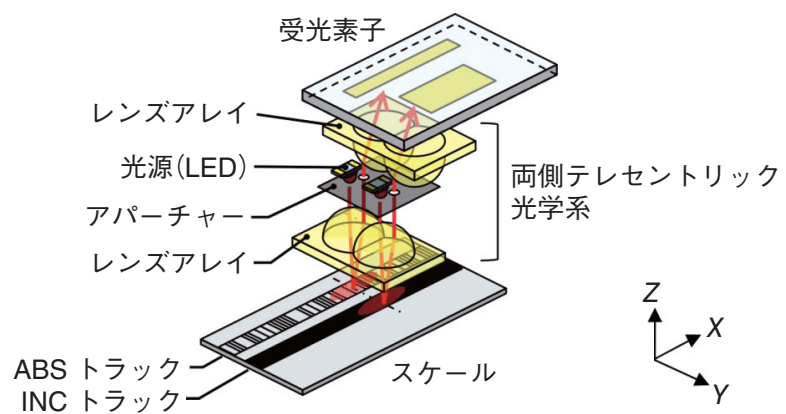

図 6 光学系構成図 (斜視図)

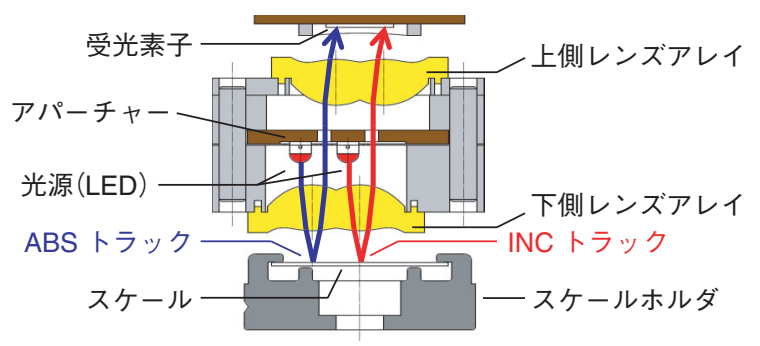

図 7 光学系構成図 $(X$ 軸方向から見た断面図 $)$

である. ABS 検出長は最大 $12 \mathrm{~m}$ であり，スケールは薄い テープ状としている，表２に主な仕様を示す。

開発した撮像光学系には, 両側テレセントリック光学系 を採用した，本光学系の構成図を図 6 および図 7 に示す。

光源 (LED) から出た光は, 下側のレンズを通してト ラック面を照明する。トラックで反射した光は下側と上側 のレンズで構成される両側テレセントリック光学系によっ て受光素子上にトラックパターンを結像している，スケー ルには INCトラックと ABS トラックが並列に配置されて いるので，この光学系を 2 系統配置している.

本光学系は, テレセントリック光学系であるので焦点深 度が深く, スケールのうねりや受光素子の $Z$ 方向の取り 付け位置の影響を大きく受けずにパターンを検出できる. このことは，機械へ取り付けるときの姿勢許容拡大という メリットがある.

また，スケールを正反射する光のみを検出するので，ス ケール上に付着している油滴などによって曲がってしまう 光を検出することがなく，その結果油滴などの影響を受け にくい．さらには，検出測長方向の検出視野を拡げること でスケール面上の污れの影響をさらに少なくしている.

\section{5. 光電式 $A B S$ リニアエンコーダの変位検出}

\section{1 変位検出の高精度化}

一般的に, レンズ光学系を通した結像パターンには高調 波成分が含まれていて，それをそのまま内挿処理を行うと 大きな誤差が生じてしまう。 そこで, 光学系の MTF (Modulation Transfer Function) を, 図 8 に示すように, INCトラック上の光学格子 $(20 \mu \mathrm{m}$ ピッチ $)$ の高調波成分

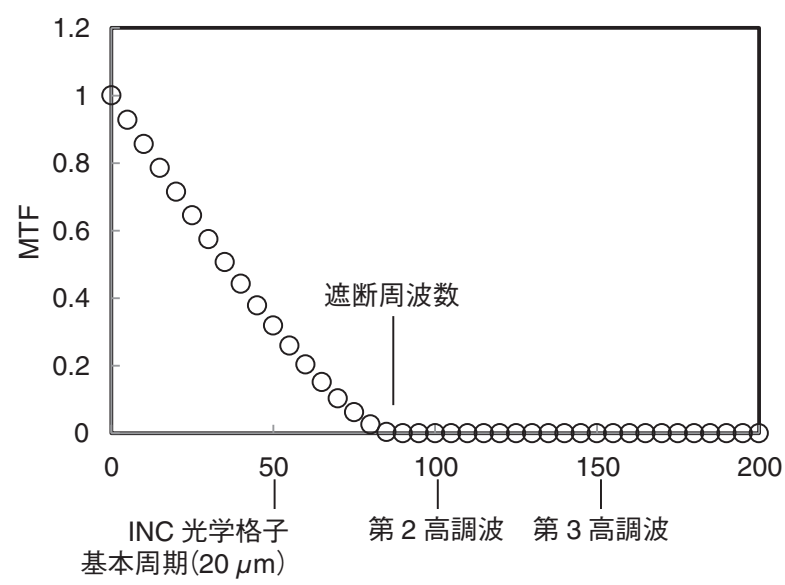

空間周波数 $(1 / \mathrm{mm})$

図 8 本テレセントリック光学系の MTF

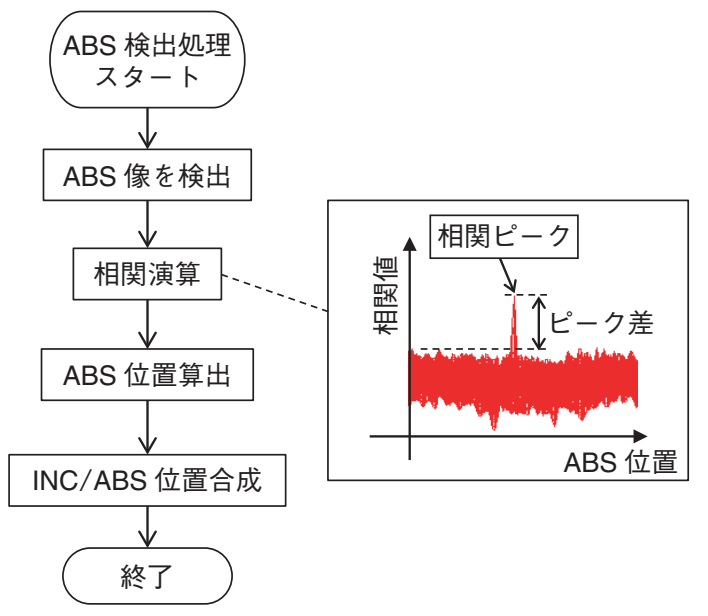

図 $9 \mathrm{ABS}$ 検出アルゴリズム

を遮断する設計とした。

しかしながら，この設計はアパーチャーの開口数を減ら し, 受光素子の検出光量を減らしてしまう。そこで, $X$ 軸方向から見たときの光路をレンズ光軸から外す非共軸構 成とした。

前掲の図 7 に示すように, 照明系と結像系の光路との間 にわずかに角度がついているため, 反射光学系でよく使用 されるビームスプリッタを用いずに照明系と結像系の光路 を分離できており，これによって受光光量の確保を図って いる.

\section{2 絶対位置の検出}

筆者らは過去に, 光電式と静電容量式を複合した ABS 検出長 $3 \mathrm{~m}$ の ABS リニアエンコーダを開発し ${ }^{4)}$, 部品構 成の簡単さもあって長年使用されている。しかしながら， $\mathrm{ABS}$ 検出長に対する近年の要求は $10 \mathrm{~m}$ を超えてきている ため, 今回スケール上に配置されたランダムパターンを使 う方法を開発した。

ABS 検出アルゴリズムについて, 処理フローを図 9 に 示す. ABSトラック上のパターンは, テレセントリック 


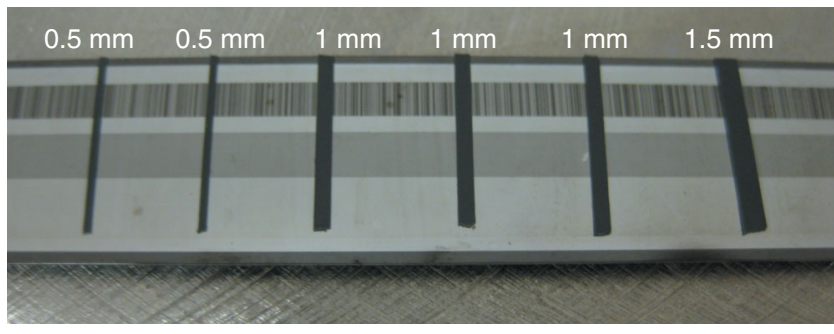

図 10 污机耐性の評価

光学系によって ABS 画像として検出され, 設計值との相 関演算をした結果得られる相関ピーク位置から ABS 検出 を行っている。このとき, 相関ピーク位置と 2 番目のピー クの差 (相関ピーク差) がゼロになると ABS 位置の誤検 出をもたらす。

光電式リニアエンコーダの場合, 污れなどによって遮光 されてしまうとスケールの情報を取得することができな い，そこで，図10に示すようにスケール上に紙片を置く ことで污れ耐性を評価した。その結果， $1.5 \mathrm{~mm}$ 幅の紙片 が置かれた状態であっても十分な相関ピーク差があり， ABS 検出が可能であることを確認した，実際の使用にあ たっては，設置環境下でのほこり，毛髪，または動作時の 油飛沫などに対して十分な耐性をもっている。

\section{6. おわりに}

絶対位置の検出機能をもつアブソリュート（ABS）リ ニアエンコーダのうち, 電磁誘導式抢よび光電式の 2 タイ プについて紹介した.

リニアエンコーダを ABS 化することで，リニアモータ の磁極検知システムや可動部の原点復帰動作が不要になる ため, 多数の可動軸をもつ装置やスケール 1 軸に対して複 数のセンサを必要とする装置などでは，特にABSリニア エンコーダの導入効果は高い. 現在 ABS リニアエンコー ダを活用されている各位，さらには今後採用を予定して扔 られる各位にとって本稿が参考になれば幸いである。

\section{参 考 文 献}

1）梶谷誠：高分解能リニアスケール，精密工学会誌，57,11 (1991) 1943

2) 坂上征司, 寺口幹也, 富谷雅樹：リニアエンコーダにおける高 性能化技術, 精密工学会誌, 61, 3 (1995) 355 .

3）堀内宰：リニアモータ, 次世代精密位置決め技術, フジ・テク ノシステム, (2000) 377.

4）桐山哲郎，下村俊隆，I. Andermo，山口庸夫：アブソリュート リニアエンコーダの開発，精密工学会誌，61，10（1995） 1405.

5）株式会社ミットヨ：誘導型位置検出装置, 特許第 3366855 号 ほか

6) http://www.heidenhain.com/

7) http://www.magnescale.com/

8) http://www.nikon.co.jp/

9) http://www.numerikjena.de/

10) http://www.renishaw.com/

11) http://www.mitutoyo.co.jp/

12）坂上征司, 桐山哲郎, 荻原元徳：リニアエンコーダの高分解能 化技術，計測と制御，44，10（2005）662.

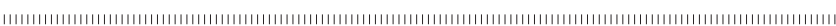

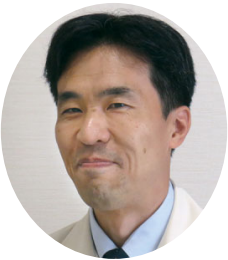
森 洋篤

1998 年東京農工大学大学院工学研究科機械シス テム工学専攻博士前期課程修了. 現在, (株)ミ ツトヨ研究開発本部商品開発部にてリニアエン コーダの商品開発に従事.

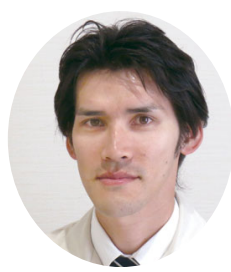

\section{小野林季}

2008 年東北大学大学院理学研究科化学専攻博士 前期課程修了。現在，(株)ミツトヨ研究開発本 部デイバイス技術開発部にてリニアエンコーダ の要素技術開発に従事.

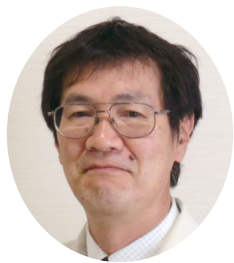

夜久 亨

1986 年電気通信大学電気通信学部電波通信学科 卒業. 現在, (株)ミツトヨ研究開発本部ディバ イス技術開発部にてリニアエンコーダの要素技 術開発に従事. 